\title{
B chromosomes and developmental homeostasis in the yellow-necked mouse, Apodemus flavicollis (Rodentia, Mammalia): Effects on nonmetric traits
}

\author{
J Blagojević and M Vujošević \\ Department of Genetics, Institute for Biological Research 'Siniša Stanković, Belgrade 11060, Serbia and Montenegro
}

\begin{abstract}
B chromosomes are found in almost all populations of the yellow-necked mouse, Apodemus flavicollis (Rodentia, Mammalia). Their effects on developmental homeostasis in this species were analyzed using morphological nonmetric traits (number of foramina) in a sample of 218 animals from locality Mt Jastrebac in the former Yugoslavia. Variations of the parameters of developmental homeostasis (the degree of fluctuating asymmetry - FA, the number of asymmetrical characters per individual - NA, and the total phenotypic variability - PV) were examined in three groups: in animals without Bs, with one B chromosome, and with more than one $B$ chromosome. Significant differences in the level of FA between groups of animals were found for two characters. Carriers of one B chromosome displayed the highest level of
\end{abstract}

phenotypic variability. Parameters of developmental stability (DS) were monitored in the population in which significant variations in the frequency of animals with Bs (fB) were established during the season earlier. The FA levels for four foramina out of a total of 12 examined followed the changes of frequencies of animals with Bs. Furthermore, a significant seasonal correlation between NA and $f B$ was found. The presence of $B$ does not cause a disturbance of homeostasis in a way that allows changes in homeostasis to be directly related to $B$ chromosome's presence. However, carriers of $B$ react differently to environmental changes than do noncarriers.

Heredity (2004) 93, 249-254. doi:10.1038/sj.hdy.6800460 Published online 21 April 2004

Keywords: B chromosomes; foramina; fluctuating asymmetry; phenotypic variability

\section{Introduction}

B chromosomes (Bs) are accessory genomic elements that occur in many species, from all the major taxonomic groups except birds. It is widely accepted that they originate from A chromosomes, although other possibilities have been suggested (Camacho et al, 2000). Their dispensable nature is the only property that is shared by all Bs. Other features, including non-Mendelian inheritance, heterochromatinization, a different morphology relative to A chromosomes, and nonpairing with As, although common, are properties that are not shared by all Bs (Jones and Rees, 1982; Vujošević, 1993).

Despite many attempts to link them with phenotypic and environmental variations, the adaptive significance of Bs in populations is largely unknown. In mammals, Bs are found in about 50 species. The effects of their presence on population biology are not understood (Vujošević, 1993). Bs are common in the yellow-necked mouse, Apodemus flavicollis (Soldatovic et al, 1975; Kral et al, 1979; Giagia et al, 1985; Sablina et al, 1985; Vujošević et al, 1991; Nadjafova et al, 1993; Boeskorov et al, 1995 and Zima and Macholán, 1995). Molecular markers that are unique to the DNA of Bs were demonstrated in this species (Tanic et al, 2000). Substantial differences in the

Correspondence: J Blagojević, Department of Genetics, Institute for Biological Research 'Siniša Stanković', Belgrade 11060, Serbia and Montenegro.E-mail: jelenabl@ibiss.bg.ac.yu

Received 17 April 2003; accepted 23 February 2004; published online 21 April 2004 frequencies of B carriers were observed between different populations (Vujošević et al, 1991; Vujošević and Blagojević, 1994; Zima and Macholán, 1995). In this species, constant, apparently equilibrium frequencies of Bs were observed in the course of 8- year studies, notwithstanding the changes in population density (Vujošević, 1992; and unpublished data). However, significant seasonal alterations in the frequencies of animals with Bs were found when stress was caused by overcrowding (Blagojevic and Vujošević, 1995). In the absence of such stress, seasonal changes of the frequencies of animals with Bs were not significant (Vujošević and Blagojević, 1995). Furthermore, it was established that the frequency of animals with Bs positively correlated with the average number of subzero temperature days and negatively with the number of days when the daily temperature was close to the expected average. Thus, the frequencies of animals with Bs are highest under extreme climatological conditions (Vujošević and Blagojevic, 2000). Furthermore, it was observed that the presence of Bs in this species affected certain morphometric traits (Blagojevic and Vujošević, 2000). All of these findings indicate that the presence of Bs in populations of A. flavicollis may influence its population dynamics.

Information concerning the effects of Bs on growth and development is mainly based on studies in plants. In general, depending on the number of Bs, their effects are either neutral or deleterious. Advantages to individuals or populations have been found in a few cases only (Jones and Rees, 1982). It has been found that cellular and nuclear volumes positively correlate with the 
amount of DNA, which is increased by the presence of Bs. Important life history features, such as the rates of cell division, development, and metabolism, are influenced by this relationship (Gregory and Hebert, 1999). Changes in genome size that are produced by Bs can be the subject of natural selection.

The measurement of the levels of fluctuating asymmetry (FA) is an approach that can be used to study the potential effects of Bs on development. FA represent small, random, and nondirectional departures from the ideal symmetry of a bilaterally symmetrical trait (Ludwig, 1932). It is frequently used as a measure of the developmental stability (DS), which is defined as the ability of an organism to develop the same phenotype under given environmental conditions (Mather, 1953). Developmental stability can be disturbed by both environmental and genetic factors. Increasing numbers of investigations use changes in the FA as a measure of environmental quality (Clarke and McKenzie, 1987; McKenzie and Clarke, 1988; Zakharov and Yablokov, 1990; Pankakoski et al, 1992; Øxnevad et al, 1995; Auffray et al, 1999). FA has been shown to be a good statistic for characterizing the state of a population (Leary and Allendorf, 1989; Zakharov et al, 1991; Zakharov and Graham, 1992).

Both metric and meristic characteristics could be used to evaluate FA. However, meristic traits are more reliable, due to the negligible error in counting. It has been established that meristic characteristics are influenced by environmental factors (Searle, 1954; Berry and Searle, 1963; Berry, 1968; Self and Leamy, 1978).

The aim of this work was to investigate any relationship between the presence of Bs and developmental homeostasis.

\section{Materials and methods}

Specimens of yellow-necked mice were sampled from locality Mt Jastrebac (UTM: EP-30) during 1989. A total of 247 animals were collected when the seasonal variability in the frequency of specimens with Bs (fB) was studied (March $\mathrm{fB}=0.40$, April $\mathrm{fB}=0.53$, May $\mathrm{fB}=0.29$, June $\mathrm{fB}=0.40$, September-October. $\mathrm{fB}=0.50$; for more details, see Blagojevic and Vujošević, 1995).

Foramina are small openings in the skull for nerves and blood vessels. Paired foramina on the cleaned skull under a dissecting binocular microscope (magnification $\times 16$ ) were counted. In all, 12 foramina on the skull and mandible were scored according to Larina and Eremina (1988): Fsf - foramen squamae frontalis; Fs - foramen squamosis; Fd - foramen diastemae; Fpal - foramen palatinum; Fh - foramen hypoglossum; Foa - foramen orbitalis anterior; Fos - foramen orbitalis superior; Fam - foramen alveolaris maxillaris; Fas - foramen alisphenoideum; Fas - foramen ovale; Fm - foramen mentale; and Fmb - foramen mentale $b$. The foramina were counted without any prior knowledge of the presence or absence of Bs in the respective animals. Furthermore, they were counted and doublechecked by one person (JB). Damaged skulls were discarded, so, in total, 218 skulls were analyzed (March $N=47$, April $N=81$, May $N=64$, June $N=14$ and September-October $N=12$ ).

For each foramen pair, DA was assessed by the signed differences between sides (Palmer, 1994). All DA values were summarized to give a character DASUM that was useful as an overall indicator of DA (Leamy et al, 1998). The level of DA was tested by the paired $t$-test. All probabilities generated in these tests were estimated for significance by the sequential Bonferroni procedure (Rice, 1989). To rule out the presence of antisymmetry $(R-L)$, values and DASUM were tested for skewness and kurtosis. The significance of the dependence of FA on size was tested by linear regression of $R-L$ on body length (measured by a caliper with $0.5 \mathrm{~mm}$ accuracy). FA was defined by absolute differences between sides (FA1) (Palmer and Strobeck, 1986). FASUM was obtained by adding all individual FA scores (Leamy et al, 1998) for each of 12 foramina. Groups without (0B), with one (1B), and with more than one $(>1 B)$ Bs were compared by the Levene test (the significance was evaluated by the sequential Bonferroni procedure).

Another measure of developmental homeostasis was the mean number of asymmetrical characters per individual (NA) (Leary et al, 1983) and the total phenotypic variability PV (Soulé, 1982; Pankakoski et al, 1987). The total phenotypic variability of the foramina was calculated as PV $=\operatorname{Var}(R+L)$.

In order to compare the NA between groups or during a particular season, one-way ANOVA was used. The medians of the variance (PV) were compared with Fridman's nonparametric test.

\section{Results}

In order to examine the effects of Bs on developmental stability, three groups were formed: (i) without Bs (comprising $57.8 \%$ of the total sample), (ii) with one B chromosome $(31.7 \%)$, and (iii) with more then one B chromosome (10.5\%). The last group consisted of animals with two Bs $(82.6 \%)$, three Bs $(13.1 \%)$, and five Bs $(4.3 \%)$. The sex ratio was close to 1:1 in all groups.

As recommended by Soulé (1967), a paired $t$-test was used to determin the significance of DA for 12 foramina analyzed and DASUM for each group separately (Table 1). To avoid type I error, the Bonferroni procedure was applied. No significant differences were detected. Differences between sides tended to be positive in sign (right side larger then the left) in all groups. Also, none of the skewness or kurtosis statistics calculated for $(R-L)$ for all foramina or DASUM was statistically significant in the sequential Bonferroni tests.

Regression $|(R-L)|$ against body length was performed in order to eliminate the size dependence of FA within samples. In all three groups, no significant levels of association were detected for any of the foramina.

The level of FA was expressed as unsigned differences (Table 2). Significant differences between groups were found for two foramina (Fst and Fs). For foramen Fst, the lowest level of FA was found in the group of animals with 1B, while the level of FA for Fs was decreasing with increased number of Bs. The overall level of FA (FASUM) was not significantly different between groups.

The mean number of asymmetrical foramina (NA) was 5.43 in the group of animals without Bs, 5.13 in the group of animals with one $B$, and 5.35 in the group of animals with more than one $B$ chromosome. The difference between the analyzed groups was not significant $\left(F_{(2,215)}=0.49\right)$. The total phenotypic variability $(\mathrm{PV})$ of the foramen numbers is presented in Table 3 . The groups 
Table 1 Indexes of DA $( \pm S E)$ in three groups: without B chromosomes $(0 \mathrm{~B})$, with one B (1B) and with more than one B chromosome ( $>1 \mathrm{~B})$

\begin{tabular}{|c|c|c|c|c|c|c|}
\hline \multirow[t]{2}{*}{ Foramen } & \multicolumn{2}{|c|}{$\begin{array}{c}B 0 \\
(\mathrm{~N}=126)\end{array}$} & \multicolumn{2}{|c|}{$\begin{array}{c}1 B \\
(\mathrm{~N}=69)\end{array}$} & \multicolumn{2}{|c|}{$\begin{array}{c}>1 B \\
(\mathrm{~N}=23)\end{array}$} \\
\hline & \multicolumn{2}{|c|}{$M e a n \pm S E$} & \multicolumn{2}{|c|}{$M e a n \pm S E$} & \multicolumn{2}{|c|}{$M e a n \pm S E$} \\
\hline Fsf & +0.111 & 0.049 & -0.014 & 0.053 & +0.043 & 0.117 \\
\hline Fs & -0.008 & 0.043 & -0.014 & 0.048 & +0.043 & 0.043 \\
\hline $\mathrm{F} d$ & +0.151 & 0.081 & +0.014 & 0.119 & 0.000 & 0.154 \\
\hline Fpal & 0.000 & 0.084 & +0.072 & 0.093 & +0.522 & 0.207 \\
\hline Fh & -0.135 & 0.060 & +0.203 & 0.087 & +0.043 & 0.117 \\
\hline Foa & +0.175 & 0.067 & +0.217 & 0.107 & +0.217 & 0.140 \\
\hline Fos & +0.095 & 0.067 & +0.275 & 0.111 & +0.043 & 0.160 \\
\hline Fam & -0.103 & 0.104 & -0.058 & 0.143 & -0.391 & 0.233 \\
\hline Fas & -0.024 & 0.078 & +0.072 & 0.124 & -0.261 & 0.157 \\
\hline Fov & +0.016 & 0.080 & -0.029 & 0.099 & -0.130 & 0.158 \\
\hline $\mathrm{Fm}$ & +0.095 & 0.105 & -0.058 & 0.130 & +0.174 & 0.279 \\
\hline $\mathrm{F} m b$ & -0.000 & 0.091 & +0.116 & 0.131 & -0.087 & 0.198 \\
\hline DASUM & +0.373 & 0.261 & +0.497 & 0.395 & +0.217 & 0.499 \\
\hline
\end{tabular}

Table 2 Indexes of FA in three groups: without B chromosomes (0B), with one B (1B) and with more than one B chromosome ( $>1 \mathrm{~B})$ and results of the Levene test

\begin{tabular}{|c|c|c|c|c|c|c|c|}
\hline & \multicolumn{3}{|c|}{$F A=|R-L|$} & \multicolumn{2}{|c|}{ Levene test } & \multirow[t]{2}{*}{$F_{(2,215)}$} & \multirow[t]{2}{*}{ P-value (*) } \\
\hline & $\begin{array}{c}0 B \\
(\mathrm{~N}=126)\end{array}$ & $\begin{array}{c}1 B \\
(\mathrm{~N}=69)\end{array}$ & $\begin{array}{c}>1 B \\
(\mathrm{~N}=23)\end{array}$ & MS Effect & MS Error & & \\
\hline Fsf & 0.302 & 0.188 & 0.304 & 0.339 & 0.049 & 6.927 & 0.013 \\
\hline Fs & 0.183 & 0.159 & 0.043 & 0.475 & 0.085 & 5.607 & 0.048 \\
\hline $\mathrm{Fd}$ & 0.595 & 0.652 & 0.435 & 0.121 & 0.121 & 0.995 & ns \\
\hline Fpal & 0.651 & 0.478 & 0.783 & 0.142 & 0.096 & 1.473 & ns \\
\hline $\mathrm{Fh}$ & 0.405 & 0.464 & 0.304 & 0.113 & 0.046 & 2.459 & ns \\
\hline Foa & 0.444 & 0.594 & 0.478 & 0.103 & 0.082 & 1.262 & ns \\
\hline Fos & 0.429 & 0.565 & 0.478 & 0.325 & 0.115 & 2.818 & ns \\
\hline Fam & 0.937 & 0.913 & 0.870 & 0.063 & 0.335 & 0.188 & ns \\
\hline Fas & 0.563 & 0.623 & 0.522 & 0.334 & 0.115 & 2.916 & ns \\
\hline Fov & 0.587 & 0.522 & 0.391 & 0.046 & 0.093 & 0.499 & ns \\
\hline $\mathrm{Fm}$ & 0.698 & 0.580 & 0.870 & 0.276 & 0.097 & 2.843 & ns \\
\hline $\mathrm{F} m b$ & 0.683 & 0.696 & 0.696 & 0.261 & 0.176 & 1.482 & ns \\
\hline FASUM & 6.476 & 6.435 & 6.174 & 1.270 & 2.420 & 0.525 & ns \\
\hline
\end{tabular}

$\left({ }^{*}\right) P$ values after sequential Bonferroni correction. $\mathrm{ns}=$ nonsignificant.

Table 3 Level of phenotypic variability (PVx10) of foramen number in the three studied groups: without $\mathrm{B}$ chromosomes $(0 \mathrm{~B})$, with one $\mathrm{B}$ (1B) and with more then one B chromosome ( $>1 \mathrm{~B})$

\begin{tabular}{lccc}
\hline Foramen & $0 B$ & $1 B$ & $>1 B$ \\
\hline Fsf & 0.88 & 0.89 & 1.11 \\
Fs & 0.89 & 0.92 & 0.91 \\
Fd & 3.46 & 4.63 & 2.57 \\
Fpal & 6.00 & 6.35 & 8.38 \\
Fh & 2.38 & 2.62 & 4.03 \\
Foa & 2.31 & 2.96 & 2.83 \\
Fos & 2.07 & 2.23 & 2.11 \\
Fam & 9.78 & 6.11 & 3.28 \\
Fas & 5.00 & 6.62 & 3.09 \\
Fov & 3.07 & 4.05 & 2.60 \\
Fm & 6.52 & 7.77 & 5.89 \\
Fmb & 9.15 & 11.69 & 6.34 \\
Median & & & 1.75 \\
\hline
\end{tabular}

differed significantly in the level of PV $\left(\chi_{(12,2)}^{2}=8.17\right.$, $P<0.02)$. The group of animals with one $\mathrm{B}$ chromosome had the highest, while the group of animals without Bs had the lowest average level of PV for the analyzed foramina.

At the Mt Jastrebac locality during the year of investigation, the change of frequency of specimens with Bs that was monitored from March to October displayed significant differences in frequency between sampling times (Blagojevic and Vujošević, 1995). For all 12 foramina, seasonal variations in the level of the FA were analyzed and compared with the variation in the frequency of animals with Bs. For four foramina, the level of the FA mostly followed changes in the frequency of animals with Bs (Figure 1a), but without any statistical significance. This was the consequence of the differences that were displayed by the last two samples. It should be noted that these four foramina show a statistically significant decrease in the level of the FA, from April to May sample, which correlated with the changes of $\mathrm{fB}$. The number of asymmetrical foramina (NA) was examined. The number of asymmetrical foramina $\left(F_{(4,229)}=3.96, P<0.005\right)$ also exhibited seasonal variations. The correlation between the frequency of animals with Bs and the number of asymmetrical foramina was statistically significant $r=0.91, P<0.05$ (Figure $1 b$ ). 


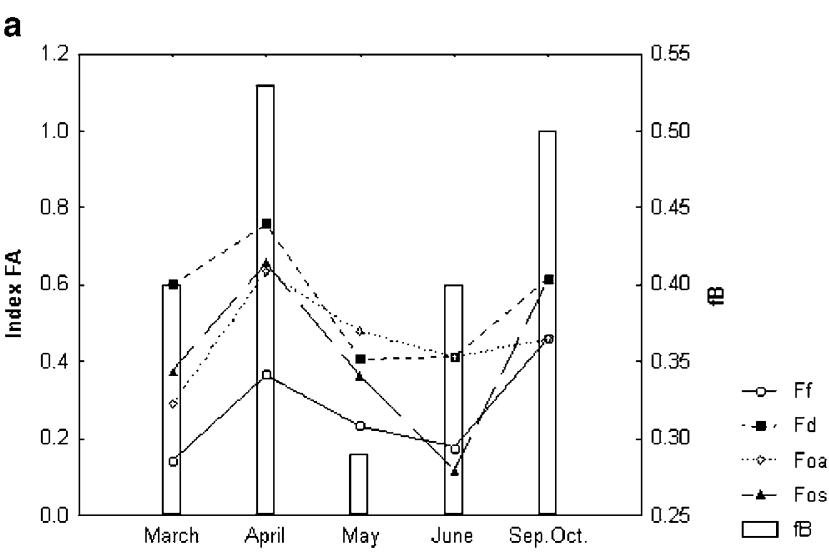

b

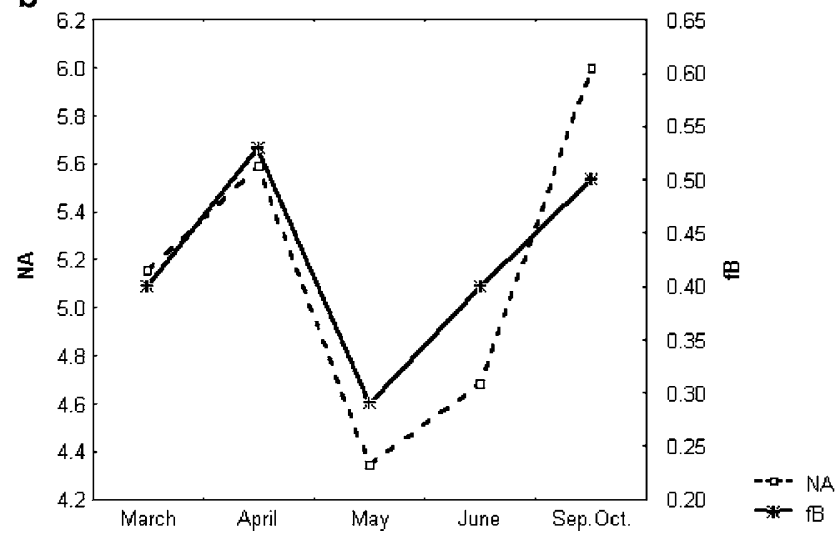

Figure 1 (a) Relationship between the indices of fluctuating asymmetry for four foramina and $\mathrm{fB}$ during the season. (b) Seasonal changes in the number of asymmetric foramina (NA) and $\mathrm{fB}$ during the season.

\section{Discussion}

The effects of Bs on development are not well known, especially in animals (Jones and Rees, 1982). In males of the grasshopper, Myrmeleotetix maculatus (Hewitt and East, 1978), development is slower in the presence of more than one B chromosome. The presence of Bs in males of the mealy bug, Pseudococcus obscurus, reduces the rate of development and number of spermatozoa (Nur, 1969). The most probable mode by which Bs affect development is by increasing the amount of genetic material, which in turn affects the duration of cell division. These theoretical expectations were confirmed in plants (Evans et al, 1972).

Skull foramina are morphological structures whose bilateral symmetry probably bares no importance for the fitness of an organism. Thus, they are very useful in investigations of developmental homeostasis. The prenatal period is critical for the development of skull foramina (Zakharov et al, 1991). The unchanging environment during intrauterine development decreases the effects of external environmental variations (Novak et al, 1993). Prolonged development in perturbed environments increases the effects of stress.

In general, analysis of our results revealed that differences in the levels of FA between different groups of animals (in specimens without, with one and with more than one B chromosome) are small and without any obvious trend.

Significant differences in phenotypic variability among the groups analyzed point to the possibility of differential effects of natural selection under adverse environmental conditions. The group of animals with one B chromosome possesses a higher level of phenotypic variability. Our previous results showed that under conditions of overcrowding, animals with one B chromosome were preferentially eliminated from the population (Blagojevic and Vujošević, 1995). The increase of the PV in this group could explain preferential selection. The observed differences, although not very pronounced, were nevertheless not negligible.

The number of asymmetrical foramina (NA) is negatively correlated with developmental homeostasis. Namely, a decrease of developmental homeostasis was accompanied by an increase of the average number of asymmetrical foramina. The differences in the NA between animals with and without Bs were not significant. However, when seasonal changes were considered, variation of the NA significantly correlated with the frequency of specimens possessing Bs. The levels of the FA in one-third of the foramina analyzed followed the changes in frequency of animals with Bs in a similar manner. This trend was significant when the first three seasonal samples, which were large, were considered. Two explanations are possible: (i) specimens with Bs had a lower level of developmental stability; thus, an increase in the frequency of these specimens in the population was accompanied by decreased developmental homeostasis; and (ii) environmental factors influenced both developmental homeostasis and the frequency of animals with Bs.

The frequency of animals with Bs was positively correlated with the population density on Mt Jastrebac (Blagojevic and Vujošević, 1995). Carriers of one B chromosome were preferentially eliminated from the population under conditions of stress produced by overcrowding. Zakharov et al (1991) established a positive correlation between population density and developmental homeostasis in the cyclic population of Sorex araneus in Siberia. It is assumed that population density is an important negative factor that affects pregnant females. Our results also point to the population density as a significant factor in the variation in the frequency of specimens with Bs and simultaneous developmental homeostasis.

In the case of A. flavicollis, a relationship between environmental variation and DS obviously exists. However, a relationship between genetic variation resulting from the presence of Bs and DS could not be established. Similar results were obtained in the superspecies of the mole rat Spalax ehrenbergi (Auffray et al, 1999). This species is represented by five chromosomal species in the Near East. It was established that the levels of DS were very heterogeneous between different populations (presumably due to environmental effects), but did not differ between species (with different genetic effects). The authors concluded that when natural populations are studied, in the determination of developmental stability, the complementary effects of both the environment and of genomes should be considered.

The relationship between developmental stability and the functional structure of the genome, that is, its 
chromosomal organization, is not clear. Chatti et al (1999) found that Robertsonian fusions in Mus musculus could produce developmental instability. Yet, in the same species, Auffray et al (2001) found that a single stable or spontaneous balanced structural rearrangement (Robertsonian fusions) did not cause a disturbance in developmental stability.

The presence of Bs, by itself, does not disturb homeostasis in a manner that could be explicitly assigned to their presence. Nevertheless, carriers of Bs react differently to environmental changes than do noncarriers. The presence of Bs expands the genetic variability of populations of $A$. flavicollis, allowing this species to be less vulnerable to environmental changes.

\section{Acknowledgements}

This work was supported by Ministry of Science, Technology and Development of Serbia, Contract No. 1693.

\section{References}

Auffray J-C, Fontanillas P, Catlan J, Britton-Davidian J (2001). Developmental stability in house mice heterozygous for single Robertsonian fusions. J Heredity 92: 23-29.

Auffray J-C, Renaud S, Alibert P, Nevo E (1999). Developmental stability and adaptive radiation in the Spalax ehrenbergi superspecies in the Near-East. J Evol Biol 12: 207-221.

Berry RJ (1968). The Biology of nonmetrical variation in mice and men. In: Brothwell RD (ed) The Skeletal Biology of Earlier Human Populations. Pergamon Press: New York, pp 103-133.

Berry RJ, Searle AG (1963). Epigenetic polymorphism in rodents. Proc R Soc Lond Ser B 140: 577-615.

Blagojević J, Vujošević M (1995). The role of B chromosomes in to the population dynamics of yellow-necked wood mice Apodemus flavicollis (Rodentia, Mammalia). Genome 38: 472-478.

Blagojević J, Vujošević M (2000). Do B chromosomes affect morphometric characters in yellow-necked mice Apodemus flavicollis (Rodentia, Mammalia)? Acta Theriol 45: 129-138.

Boeskorov GG, Kartavseva IV, Zagordnyk IV, Belyanin AN, Lyapunova, EA (1995). Nucleolar organizer regions and B-chromosomes of wood mice (Mammalia, Rodentia, Apodemus). Russ J Genet 31: 156-163.

Camacho JPM, Sharbel TF, Beukeboom LW (2000). B chromosome evolution. Philos Trans $R$ Soc 355: 163-178.

Chatti N, Said K, Catalan J, Britton-Davidian J, Auffray J-C (1999). Developmental stability in wild chromosomal hybrids of the house mouse. Evolution 53: 1268-1279.

Clarke GM, McKenzie AJ (1987). Developmental stability of insecticide resistant phenotypes in blowfly: a result of canalising natural selection. Nature 325: 345-346.

Evans GM, Rees H, Snell CL, San S (1972). The relationship between nuclear DNA amount and the duration of the mitotic cycle. Chromosome Today 3: 24-31.

Giagia E, Soldatović B, Savić I, Zimonjić D (1985). Karyotype study of the genus Apodemus (Kaup, 1829) populations from Balkan peninsula. Acta Vet 35: 289-298.

Gregory TR, Hebert PDN (1999). The modulation of DNA: proximate causes and ultimate consequences. Genome Res 9: 317-324.

Hewitt SM, East MT (1978). Effects of B chromosomes on development in grasshopper embryos. Heredity 41: 347-356.

Jones RN, Rees H (1982). B Chromosomes. Academic Press: London.

Kral B, Zima J, Herzig-Straschil B, Streba O (1979). Karyotypes of certain small mammals from Austria. Folia Zool 28: 5-11.
Larina IN, Eremina VI (1988). Catalogue of basic cranial characteristics in rodents. In: Phenetics of Natural Populations. (in Russian). Collection of Scientific Papers, Nauka: Moskva, pp 8-52.

Leamy J, Routman JE, Cheverud MJ (1998). Quantitative trait locy for fluctuating asymmetry of discrete skeletal characters in mice. Heredity 80: 509-518.

Leary RF, Allendorf FW (1989). Fluctuating asymmetry as an indicator of stress: Implications for conservation biology. TREE 4: 214-217.

Leary RF, Allendorf FW, Knudsen LK (1983). Developmental stability and enzyme heterozygosity in rainbow trout. Nature 301: 71-72.

Ludwig W (1932). Das Rechst-Links Problem in Teirreich und beim Menschen. Springer: Berlin, 496pp.

Mather K (1953). Genetical control of stability in development. Heredity 7: 297-336.

McKenzie JA, Clarke GM (1988). Diazanon resistence, fluctuating asymmetry and fitness in Australian sheep blowfly, Lucilia cuprina. Genetics 120: 213-220.

Nadjafova RS, Bulatova NS, Chasovlikarova Z, Gerassimov S. (1993). Karyological differences between two Apodemus species in Bulgaria. Z. Saügetierkunde 58: 232-239.

Novak MJ, Rhodes OE, Smith MH, Chesser RK (1993). Morphological asymmetry in mammals: genetic and homeostasis reconsidered. Acta Theriol 38(suppl): 7-18.

Nur U (1969). Mitotic instability leading to an accumulation of B chromosomes in grasshoppers. Chromosoma 27: 1-19.

Øxnevad SA, Østbae K, Vøllestad LA (1995). Year class variation in fluctuating asymmetry in perch (Perca fluviatilis L.) from an acidic aluminium-rich lake. Ecol Freshwater Fish 4: 131-137.

Palmer AR (1994). Fluctuating asymmetry analysis: A primer. In: Markow TA (ed) Developmental instability: its origins and evolutionary implications. Kluwer Academic Publishers: Dordrecht, pp 336-364.

Palmer AR, Strobeck C (1986). Fluctuating asymmetry: measurement, analysis, patterns. Annu Rev Ecol Syst 17: 391-421.

Pankakoski E, Koivisto I, Hyvärinen H (1992). Reduced developmental stability as an indicator of heavy metal pollution in the common shrew Sorex araneus. Acta Zool Fenn 191: 137-144.

Pankakoski E, Väisänen AR, Nurmi K (1987). Variability of muskrat skulls: measurement error, environmental modification and size allometry. Syst Zool 36: 35-51.

Rice WR (1989). Analyzing table of statistical tests. Evolution 43 : 223-225.

Searle AG (1954). Genetical studies on the skeleton of the mouse. IX. Causes of skeletal variation within pure lines. J Genet 52: $68: 102$.

Sablina OV, Radjabli SI, Golenischcev FN (1985). B-chromosomes in the karyotype of Apodemus flavicollis from Leningrad District. Zool J 64: 1901-1903.

Self S, Leamy L (1978). Heritability of quasi-continuous skeletal traits in a randombred population of house mice. Genetics 88: 109-120.

Soldatović B, Savić I, Seth P, Reichstein H, Tolksdorf M (1975). Comparative karyological study of the genus Apodemus. Acta Vet 25: 1-10.

Soulé EM (1967). Phenetics of natural populations. II. Asymmetry and evolution in a lizard. Am Nat 101: 141-160.

Soule EM (1982). Allometric variation. 1. The theory and some consequences. Am Nat 6: 751-764.

Tanić N, Dedović N, Vujošević M, Dimitrijević B (2000). DNA profiling of B-chromosomes from the yellow-necked mouse Apodemus flavicollis (Rodentia, Mammalia). Genome Res 1: 55-61.

Vujošević M (1992). B-chromosome polymorphism in Apodemus flavicollis (Rodentia, Mammalia) during five years. Caryologia 3-4: 347-352. 
Vujošević M (1993). B-chromosomes in mammals. Genetika (Belgrade) 3: 247-258.

Vujošević M, Blagojević J (1995). Seasonal changes of Bchromosome frequencies within the population of Apodemus flavicollis (Rodentia) on Cer mountain in Yugoslavia. Acta Theriol 40: 131-137.

Vujošević M, Blagojević J (1994). New localities with B chromosome in Apodemus flavicollis (Rodentia, Mammalia). Arch Biol Sci 3-4: 15.

Vujošević M, Blagojević J, Radosavljević J, Bejaković D (1991). B chromosome polymorphism in populations of Apodemus flavicollis in Yugoslavia. Genetica 83: 167-170.
Vujošević M, Blagojević J (2000). Does environment affect polymorphism of B chromosomes in the yellow-necked mouse Apodemus flavicollis? Z. Sagetierkunde 65: 313-317.

Zakharov MV, Graham JH (1992). Developmental stability in natural populations. Acta Zool Fenn 191: 1-2.

Zakharov MV, Pankakoski E, Sheftel IB, Peltonen A, Hanski I (1991). Developmental stability and population dynamics in common shrew, Sorex araneus. Am Nat 138: 797-810.

Zakharov MV, Yablokov AV (1990). Skull asymmetry in the baltic grey seal: effects of environmental pollution. Ambio 5: 266-269.

Zima J, Macholán M (1995). B chromosomes in the wood mice (genus Apodemus). Acta Theriol 3: 75-86. 